Supporting Information to

\title{
Ionic Strength Gated Redox Current Rectification by Ferrocene Grafted in Silica Nanochannels
}

\author{
Lei Sun ${ }^{\text {a }}$, Lin Zhou ${ }^{\text {a }}$, Fei Yan ${ }^{\mathrm{b}}$, and Bin $\mathrm{Su}^{\mathrm{a}}{ }^{\text {, }}$
}

${ }^{a}$ Institute of Analytical Chemistry, Department of Chemistry, Zhejiang University, Hangzhou 310058, China

${ }^{b}$ Department of Chemistry, Zhejiang Sci-Tech University, Hangzhou 310018, China

* Corresponding author. E-mail: subin@zju.edu.cn

\section{Table of Contents}

S1. ${ }^{1} \mathrm{H}$ NMR spectrum of FcM-PhDA

S2. $i$ - $t$ response of Fc@SNM/ITO electrode

S3. CVs characterization of SNM/ITO after etching the SNM

S4. CVs characterization of Fc@ ITO after alkaline treatment

S5. The effect of scan rate on the CVs response

S6. Calculation of Surface Coverage of Fc molecules on the Fc@SNM/ITO Electrode

S7. Stability of the Fc@SNM/ITO Electrode

S8. CVs of $\mathrm{Fe}(\mathrm{CN})_{6}{ }^{4-}$ and $\mathrm{IrCl}_{6}{ }^{2-}$ at the SNM/ITO electrode

S9. Rectification ratio at various concentrations of redox species 


\section{S1. ${ }^{1} \mathrm{H}$ NMR spectrum of FcM-PhDA}

FcM-PhDA was synthesized via Schiff base reaction as reported previously and characterized by ${ }^{1} \mathrm{H}$ NMR. ${ }^{\mathrm{S} 1,2}{ }^{1} \mathrm{H}$ NMR measurements were performed on a Bruker Avance-400 spectrometer at room-temperature using $\mathrm{CDCl}_{3}$ as solvent. As shown in Figure S1, ${ }^{1} \mathrm{H}$ NMR: $\delta 3.37\left(\mathrm{~s}, 3 \mathrm{H}, \mathrm{NH}, \mathrm{NH}_{2}\right) ; 3.91\left(\mathrm{~s}, 2 \mathrm{H}, \mathrm{CH}_{2}\right) ; 4.13(\mathrm{t}, 2 \mathrm{H}, \mathrm{J}=2.0$ $\left.\mathrm{Hz}, \mathrm{C}_{5} \mathrm{H}_{4}\right) ; 4.17\left(\mathrm{~s}, 5 \mathrm{H}, \mathrm{C}_{5} \mathrm{H}_{5}\right) ; 4.23\left(\mathrm{t}, 2 \mathrm{H}, \mathrm{J}=2.0 \mathrm{~Hz}, \mathrm{C}_{5} \mathrm{H}_{4}\right) ; 6.58(\mathrm{~d}, 2 \mathrm{H}, \mathrm{J}=8.8 \mathrm{~Hz}$, $\left.\mathrm{C}_{6} \mathrm{H}_{4}\right) ; 6.65\left(\mathrm{~d}, 2 \mathrm{H}, \mathrm{J}=8.8 \mathrm{~Hz}, \mathrm{C}_{6} \mathrm{H}_{4}\right)$.

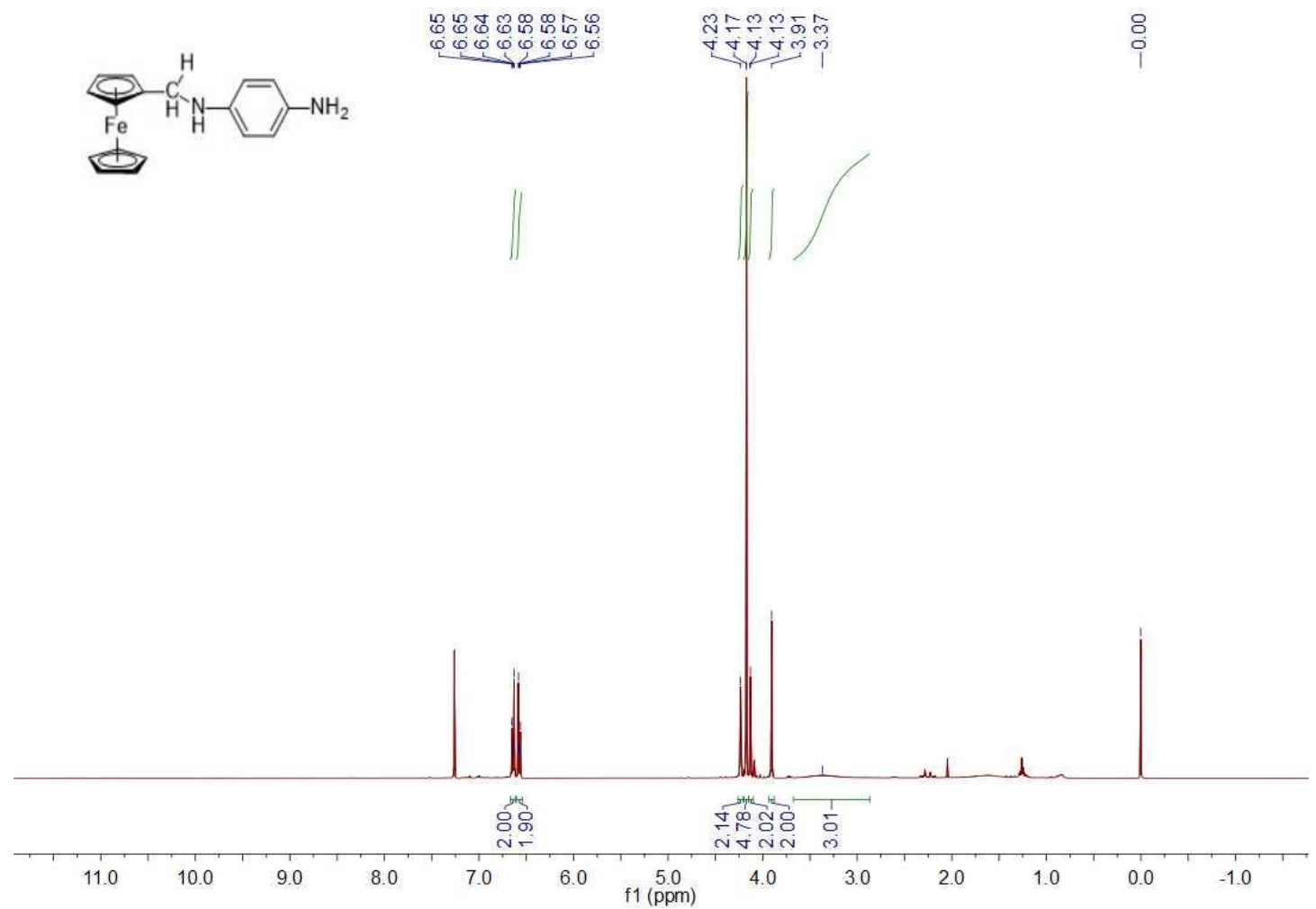

Figure S1. ${ }^{1} \mathrm{H}$ NMR spectrum of FcM-PhDA. Inset is the molecular structure of FcM$\mathrm{PhDA}$. 


\section{S2. $i$ - $t$ response of Fc@SNM/ITO electrode}

A constant potential of $-0.6 \mathrm{~V}$ (vs. $\mathrm{Ag} / \mathrm{AgCl}$ ) was biased at the SNM/ITO electrode for $50 \mathrm{~s}$ to graft FcM-PhDA molecules on the underlying surface (see Figure 1b). Figure S2 shows the $i$ - $t$ curve.

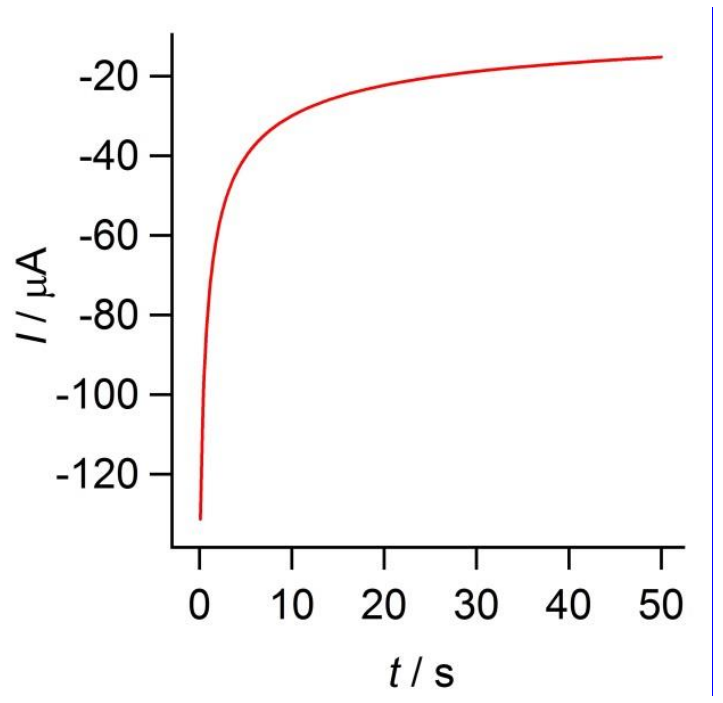

Figure S2. The $i-t$ curve of the preparation of Fc@SNM/ITO electrode by electrochemical method. The applied potential was $-0.6 \mathrm{~V}$. 


\section{S3. CVs characterization of SNM/ITO after etching the SNM}

After immersing the SNM/ITO electrode in $1 \mathrm{M} \mathrm{NaOH}$ solution, the obtained electrode termed as SNM/ITO (etched SNM) was characterized by CVs. Figure $\mathbf{S 3}$ compares the CVs of bare ITO and SNM/ITO (etched SNM) electrodes at high (a) and low (b) salt concentration using $\mathrm{Fe}(\mathrm{CN}){ }_{6}{ }^{3-}$ as probe. Clearly, the SNM/ITO (etched SNM) electrode has the same CV curves with the bare ITO in both cases, indicating that SNM has been successfully removed from the surface of ITO electrode. Moreover, as can be found in Figure 2d, SNM layer was disappeared from the top of ITO glass, further confirming the completed etching of SNM.
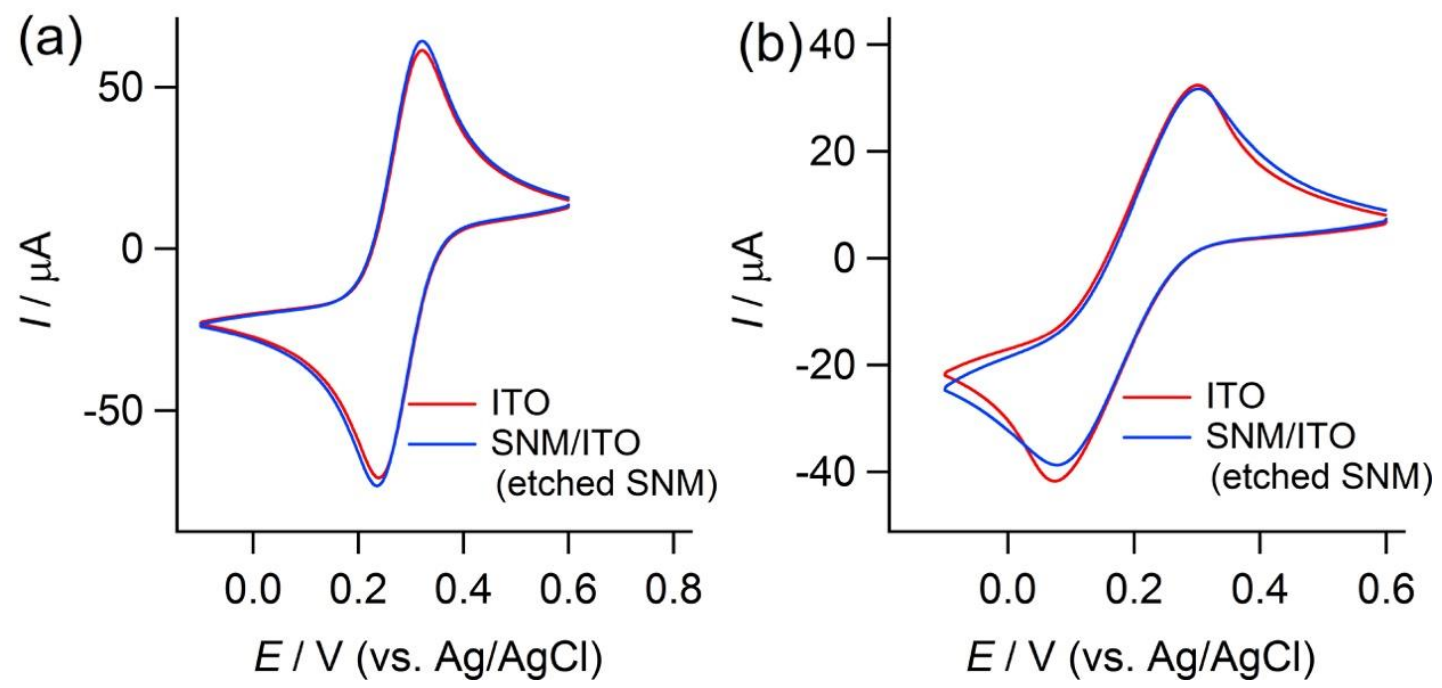

Figure S3. $(\mathrm{a}, \mathrm{b}) \mathrm{CV}$ s of the bare ITO and SNM/ITO after etching SNM from the electrode surface in $1 \mathrm{M}$ (a) or $1 \mathrm{mM}$ (b) $\mathrm{NaCl}$ solutions containing $1 \mathrm{mM} \mathrm{Fe}(\mathrm{CN}) 6^{3-}$. 


\section{S4. CVs characterization of Fc@ ITO after alkaline treatment}

After immersing the Fc@ITO electrode in $1 \mathrm{M} \mathrm{NaOH}$ solution, the obtained electrode termed as Fc@ITO $(\mathrm{NaOH})$ was characterized by CVs. Clearly, the peak current of the Fc@ITO $(\mathrm{NaOH})$ is obviously smaller than that of Fc@ITO, indicating that ferrocene groups inevitably suffer from the damage in strong alkaline solution.

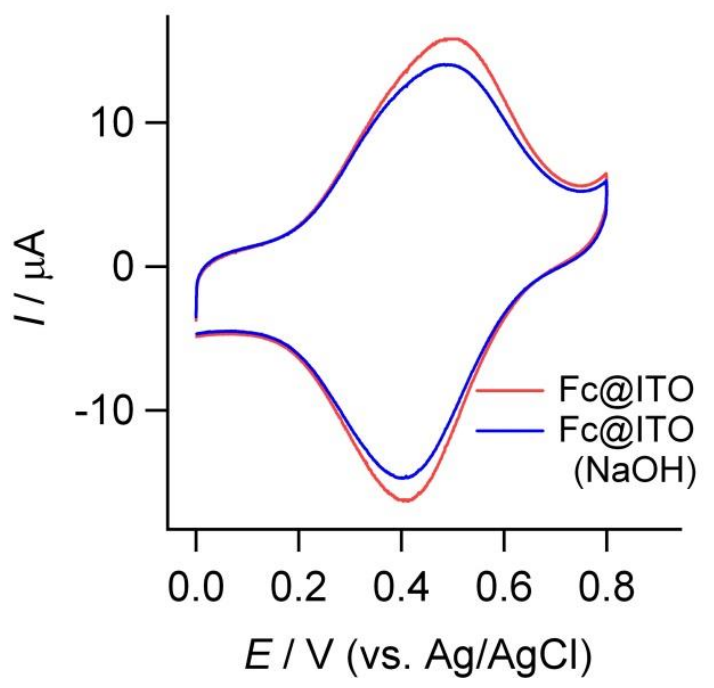

Figure S4. CVs obtained with the Fc@ITO electrode before and after being treated with $1 \mathrm{M} \mathrm{NaCl}$ solution containing $1 \mathrm{M} \mathrm{NaOH}$. The scan rate was $0.05 \mathrm{~V} \mathrm{~s}^{-1}$. 


\section{S5. The effect of scan rate on the CVs response}

Figure S5a and b shows CVs of the Fc@SNM/ITO electrode at different scan rates. Obviously, both anodic peak current and cathodic peak current linearly increase with the square root of scan rate $\left(v^{1 / 2}\right)$, indicating the electrochemical process of immobilized Fc molecules was diffusion-controlled. CVs of the Fc@/ITO (after alkaline treatment) electrode at different scan rates are also displayed in Figure S5c and d. Peak currents (both anodic peak current and cathodic peak current) are proportional to sweep speed $(v)$, indicating the electrochemical process of immobilized Fc molecules was surfacecontrolled. 

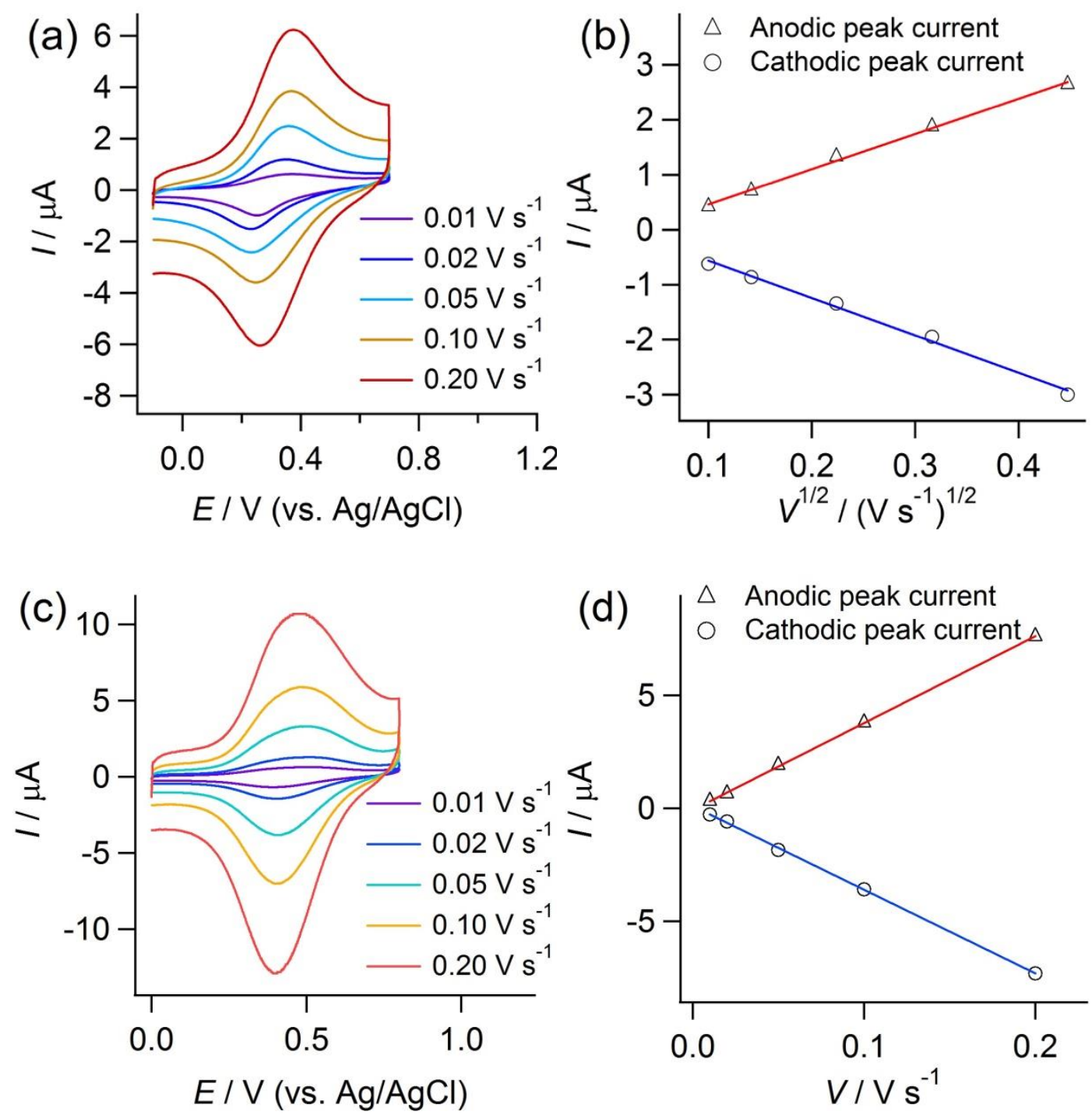

Figure S5. (a) CVs of the Fc@SNM/ITO electrode under different scan rates in $0.1 \mathrm{M}$ $\mathrm{NaCl}$ solution. (b) The linear relationship between the peak currents $\left(I_{\mathrm{p}}\right)$ and square root of the scan rate $\left(v^{1 / 2}\right)$. Anodic peak current $I_{\mathrm{pa}}=6.406 v^{1 / 2}-0.1782(R=0.9983)$, cathodic peak current $I_{\mathrm{pc}}=-6.795 v^{1 / 2}+0.1160(R=-0.9972)$. (c) CVs of the Fc@SNM/ITO (etched SNM) electrode under different scan rates in $0.1 \mathrm{M} \mathrm{NaCl}$ solution. (d) The linear relationship between the peak currents $\left(I_{\mathrm{p}}\right)$ and scan rate $(v)$. Anodic peak current $I_{\mathrm{pa}}=38.38 v-0.07358(R=0.9999)$, cathodic peak current $I_{\mathrm{pc}}=-$ $37.02 v-0.1012(R=-0.9998)$. 


\section{S6. Calculation of Surface Coverage of Fc molecules on the Fc@SNM/ITO Electrode}

The surface coverage of the immobilized Fc molecules $(I)$ on the Fc@SNM/ITO electrode could be calculated by the following equation (eq S1). ${ }^{\mathrm{S} 3}$

$$
\Gamma=\frac{Q}{n F A}
$$

where $Q$ is the integrated charge of the anodic peak shown in Figure S5a. $F, A$ and $n$ are the Faraday constant, electrode area, and electron number involved in electrode reaction, respectively. Herein we have $A=0.5 \mathrm{~cm}^{2}$ and $n=1$. The integrated charges at different scan rates $(10,20,50,100,200 \mathrm{mV} / \mathrm{s})$ are $4.68 \times 10^{-6}, 3.97 \times 10^{-6}, 3.12 \times 10^{-}$ ${ }^{6}, 2.56 \times 10^{-6}, 2.13 \times 10^{-6} \mathrm{C}$, respectively. Consequently, the corresponding surface coverages are $9.7 \times 10^{-11}, 8.2 \times 10^{-11}, 6.5 \times 10^{-11}, 5.3 \times 10^{-11}, 4.4 \times 10^{-11} \mathrm{~mol} / \mathrm{cm}^{2}$, respectively. Therefore, the average value of surface coverage was about $6.8 \times 10^{-11}$ $\mathrm{mol} / \mathrm{cm}^{2}$. This value is comparable to that of closed-packed monolayer inside the nanochannels $\left(7.2 \times 10^{-11} \mathrm{~mol} / \mathrm{cm}^{2}\right)$, corresponding to the $16.7 \%$ of closed-packed monolayer value $\left(4.3 \times 10^{-10} \mathrm{~mol} / \mathrm{cm}^{2}\right)$ on the planar electrode. ${ }^{\mathrm{S}, 4}$ In addition, in Figure S4 (red curve), we have $Q=2.02 \times 10^{-5} \mathrm{C}, n=1$ and $A=0.5 \mathrm{~cm}^{2}$. Consequently, the surface coverage $(\Gamma)$ of Fc molecules on ITO was calculated to be $4.2 \times 10^{-10}$ $\mathrm{mol} / \mathrm{cm}^{2}$, which was consistent with the theoretical value. 


\section{S7. Stability of the Fc@SNM/ITO Electrode}

The stability of Fc@SNM/ITO electrode was investigated. As shown in Figure S6a, the $\mathrm{CVs}$ response of $\mathrm{Fc} @ \mathrm{SNM} / \mathrm{ITO}$ electrode in $0.1 \mathrm{M}$ tetrabutylammonium perchlorate-acetonitrile solution decrease slightly in the continuous scanning from 0.2 V to 0.8 V (50 cycles). Figure S6b displayed the variation of anodic peak current and cathodic peak current with cycling number. As can be seen, the peak currents of Fc@SNM/ITO electrode remain pretty stable, suggesting the excellent stability of grafted Fc molecules onto the electrode surface.
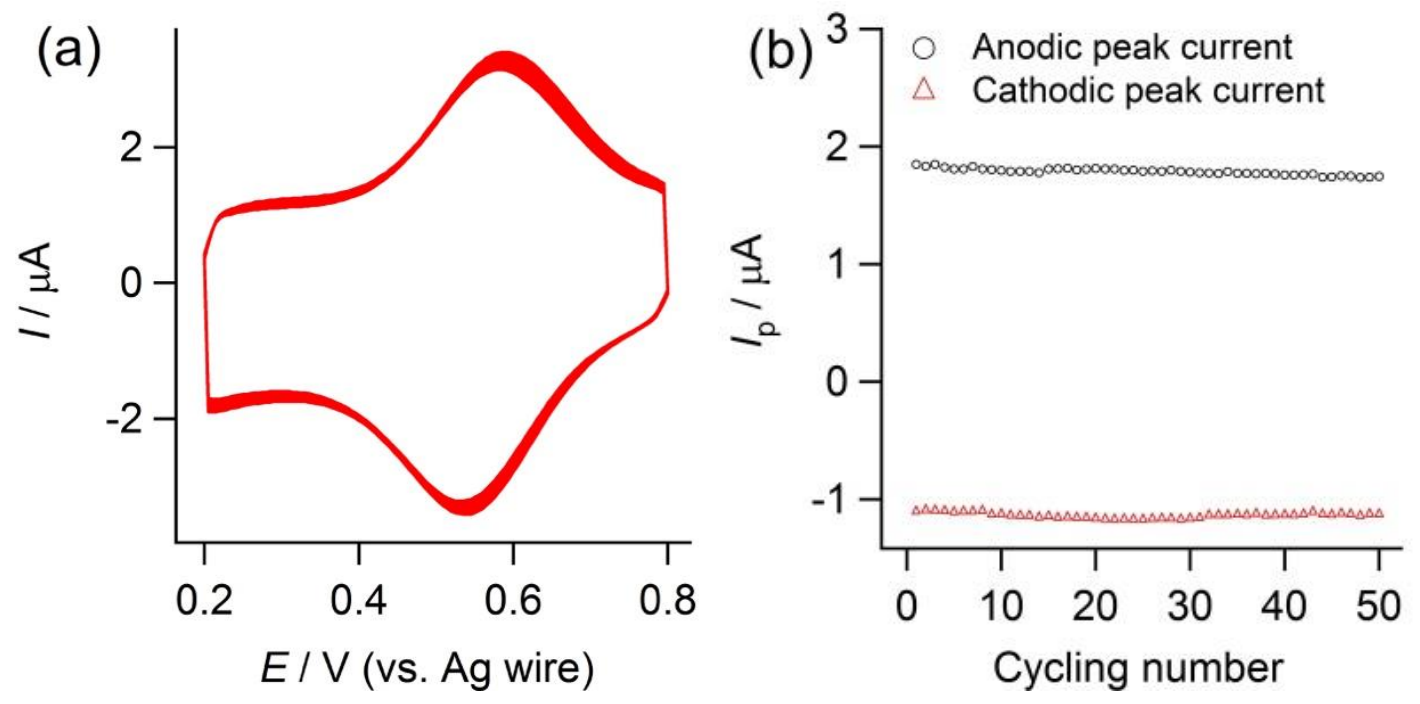

Figure S6. (a) Successive CVs response of the Fc@SNM/ITO electrode in acetonitrile solution ( $0.1 \mathrm{M}$ tetrabutylammonium perchlorate served as supporting electrolyte) between +0.2 and $+0.8 \mathrm{~V}$ at a scan rate of $0.1 \mathrm{~V} \mathrm{~s}^{-1}$. The cycling number is 50 . (b) The dependence of peak currents on continuous voltammetric cycling. 


\section{S8. CVs of $\mathrm{Fe}(\mathrm{CN})_{6}{ }^{4-}$ and $\mathrm{IrCl}_{6}{ }^{2-}$ at the $\mathrm{SNM} / \mathrm{ITO}$ electrode}

Figure S7 shows the CVs response of SNM/ITO electrode in $0.1 \mathrm{M} \mathrm{NaCl}$ solution containing $1 \mathrm{mM} \mathrm{Fe}(\mathrm{CN})_{6}{ }^{4-}$ and $\mathrm{IrCl}_{6}{ }^{2-}$. As seen, the equilibrium relative redox potential of $\mathrm{Fe}(\mathrm{CN})_{6}{ }^{4-}$, and $\mathrm{IrCl}_{6}{ }^{2-}$ are $+0.25 \mathrm{~V}$ and $+0.73 \mathrm{~V}$, respectively.

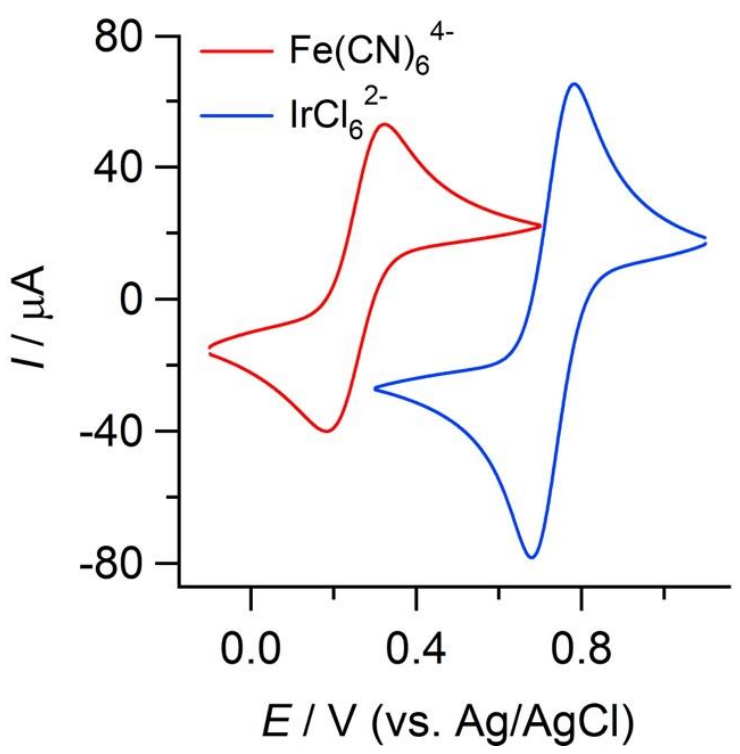

Figure S7. (a) CVs of SNM@ITO electrode in $0.1 \mathrm{M} \mathrm{NaCl}$ solution containing $1 \mathrm{mM}$ $\mathrm{Fe}(\mathrm{CN})_{6}{ }^{4-}$ (red curve) and $\mathrm{IrCl}_{6}{ }^{2-}$ (blue curve). The scan rate was $0.05 \mathrm{~V} \mathrm{~s}^{-1}$. 


\section{S9. Rectification ratio at various concentrations of redox species}

Table S1 summarized the rectification ratio at various concentrations of redox species.

The values of rectification ratio were extracted from Figures $\mathbf{5 b}$ and $\mathbf{6 b}$.

Table S1. Rectification ratio at various concentrations of $\mathrm{IrCl}_{6}{ }^{2-}$ and $\mathrm{Fe}(\mathrm{CN})_{6}{ }^{4-}$.

\begin{tabular}{ccccccccc}
\hline $\mathrm{C} / \mathrm{mM}$ & 0.1 & 0.2 & 0.3 & 0.4 & 0.5 & 1.0 & 3.0 & 5.0 \\
\hline$R_{\mathrm{Fe}(\mathrm{CN}){ }^{4}}$ & 3.24 & 4.85 & 6.55 & 7.85 & 9.26 & 16.47 & 47.84 & 86.27 \\
$R_{\mathrm{IrCl}_{6}{ }^{2-}}$ & 3.22 & 5.47 & 7.36 & 10.13 & 13.12 & 28.58 & 76.59 & 126.05 \\
\hline
\end{tabular}




\section{Reference}

[S1] Liu, W. J.; Xiong, G. X.; Wang, W. P. Research on Synthesis and Conductivity of Ferrocenyl Schiff Base and its Salt. Appl. Organomet. Chem. 2007, 21, 83-88.

[S2] Arancibia, R.; Hugo Klahn, A.; Buono-Core, G. E.; Gutierrez-Puebla, E.; Monge,A.; Medina, M. E.; Olea-Azar, C.; Maya, J. D.; Godoy, F. Synthesis, Characterization and Anti-Trypanosoma Cruzi Evaluation of Ferrocenyl and Cyrhetrenyl Imines Derived from 5-Nitrofurane. J. Organomet. Chem. 2011, 696, 3238-3244.

[S3] Tian, H. H.; Dai, Y.; Shao, H. B.; Yu, H.-Z. Modulated Intermolecular Interactions in Ferrocenylalkanethiolate Self-Assembled Monolayers on Gold. $J$. Phys. Chem. C 2013, 117, 1006-1012.

[S4] Lin, X. Y.; Yang, Q.; Ding, L. H.; Su, B. Ultrathin Silica Membranes with Highly Ordered and Perpendicular Nanochannels for Precise and Fast Molecular Separation. ACS Nano 2015, 9, 11266-11277. 